\title{
Internal Waves on the Black Sea Shelf near the Heracles Peninsula: Modeling and Observation
}

\author{
V. A. Ivanov, T. Ya. Shul'ga*, A. V. Bagaev, A. V. Medvedeva, \\ T. V. Plastun, L. V. Verzhevskaia, I. A. Svishcheva
}

Marine Hydrophysical Institute of RAS, Sevastopol, Russian Federation

*shulgaty@mail.ru

Purpose. The purpose consists in a combined analysis of satellite observations of surface manifestations of internal waves near the Crimean coast and the results of numerical simulation of influence of seasonal thermohaline conditions and the relief on their structure, dynamics and intensification.

Methods and Results. Based on the analysis of remote sensing data using high-resolution sensors of the Landsat-8 and Sentinel-2 satellites and the theoretical estimates, the main spatial and temporal characteristics of the internal waves on the Black Sea shelf near the Heracles Peninsula were determined. According to the temperature and salinity data obtained from the satellite measurements and the research vessels measurements in 1951-2008 from the Oceanographic Data Bank of Marine Hydrophysical Institute, the structure of density stratification was investigated, and buoyancy frequency profiles in the shelf and slope area from Yevpatoria to Yalta were obtained. Vertical velocity profiles of internal waves of the first three modes on the shelf were constructed. It was revealed that phase velocity of the internal waves of the first mode in the deep-sea part varied within the range of $2.6-5 \mathrm{~m} / \mathrm{s}$, the waves of the second mode - within 1.1-2.3 m/s, and the waves of the third mode - within $0.7-1.4 \mathrm{~m} / \mathrm{s}$. The average length of the waves detected from the satellite data was $0.4 \mathrm{~km}$; the longest waves, about $1.1 \mathrm{~km}$, were observed most often between Yevpatoria and Sevastopol, propagating predominantly to the northeast. Within the same train, wave dispersion occurred resulting in the wavelength diminution to $0.1-0.3 \mathrm{~km}$.

Conclusions. The stated assumption on the cause of generation of intense internal waves conditioned by the interaction of the Rim Current jet with the shelf edge was confirmed by the results of numerical calculations. Spatial and temporal characteristics of the internal waves, the integrated data of remote sensing and the modeling results make it possible to estimate vertical exchange at the shelf and to determine the depth of the maximum Brunt-Väisälä frequency.

Keywords: Black Sea, dispersion relations, mode structure, remote sensing, intense internal waves, topographic effects.

Acknowledgments: the authors are grateful to Professor Alexander E. Yankovsky, a former researcher of Marine Hydrophysical Institute currently working at the University of South Carolina (Colombia, USA) for his support of this research and advice on developing the applications for processing the data on wave oscillations. The work was carried out within the framework of the scientific project No. 18-45-920036 "Characteristics of internal waves in the region of the Heracles Peninsula: manifestation, modeling, impact on the ecosystem" supported by the Russian Foundation for Basic Research and the city of Sevastopol.

For citation: Ivanov, V.A, Shul'ga, T.Ya, Bagaev, A.V., Medvedeva, A.V., Plastun, T.V., Verzhevskaia, L.V. and Svishcheva, I.A., 2019. Internal Waves on the Black Sea Shelf Near the Heracles Peninsula: Modeling and Observation. Physical Oceanography, [e-journal] 26(4), pp. 288-304. doi:10.22449/1573-160X-2019-4-288-304

DOI: $10.22449 / 1573-160 X-2019-4-288-304$

(C) 2019, V.A. Ivanov, T.Ya. Shul'ga, A.V. Bagaev, A.V. Medvedeva, T.V. Plastun, L.V. Verzhevskaia, I.A. Svishcheva

(C) 2019, Physical Oceanography

\section{Introduction and motivation}

Increasing intensity of the use of coastal areas and shelves of the Russian seas determines the need for a qualitative forecast of all natural phenomena occurring in this area, which is especially in demand in coastal construction and tourism services. On the Black Sea shelf near the Crimean coast, there are areas with 
coastline heterogeneities, peculiar bottom topography and areas where the Rim Current jet flows close to the coast. All these factors create the prerequisites for the generation of internal waves. Sudden changes in wind velocity, relaxation of coastal upwelling and destruction of frontal and eddy formations lead to the appearance of especially intense internal waves.

Observations of internal waves on the Black Sea shelf have been performed for a long time and mainly in two areas: in Crimea at Marine Hydrophysical Institute (MHI) of RAS polygon near Katsiveli [1] and at the Caucasus coast on the north-eastern shelf near Gelendzhik [2,3]. Detailed studies of internal waves using contact methods have been performed in the shelf zones of the Caspian and Black Seas [4] for many years. The data obtained not only made it possible to study the spatial-temporal characteristics of the waves in detail, but also to study the processes underlying the generation of intense internal waves. Under conditions of a narrow shallow shelf, the generation of waves with the maximum amplitudes is associated with the income of local fronts of surge origin to the coastal zone, which is observed during the periods of weak wind stress and reconstruction of stratification violated by surges $[4,5]$. Under conditions of a wide shelf, moving surface intrusion of desalinated coastal waters can generate intense internal waves [6]. The surface manifestations of internal waves in the Black Sea were studied in [7], which described a new revealed mechanism for the formation of internal waves in tideless seas - wave generation by non-stationary front associated with the passage of a cold eddy. One of the causes for the occurrence of internal waves is the presence of vertical wake turbulence; the structure of waves generated under such conditions and their surface manifestations were studied in [8,9].

Availability of satellite images and possibility to detect and describe the internal waves have become one of the decisive factors in selecting the methods for studying their field parameters. In particular, the data obtained from artificial Earth satellites (AES) Landsat-8 (since 2013), Sentinel-1 (since 2014), Sentinel-2 (since 2015) [10-12] were used to study the surface manifestations of internal waves. Examples of experimental evidence of the internal waves relationship with their surface manifestations in the Black, Japanese, South China Seas and the Indian Ocean are given in $[13,14]$. Manifestations of internal waves in the tideless Caspian Sea are considered in [15]. Internal waves in the Black Sea differ from those in the ocean in much lower intensity, but there are more causes for their formation [16]. Thus, comparison of the results of sub-satellite studies and remote sensing data revealed a connection between internal waves and the passage of cold eddy formations $[10,17]$.

In this work, the internal waves dynamics and the conditions for their occurrence were studied based on a series of numerical experiments and satellite observations. The research is based on the study of the conditions for the generation of intense internal waves at the Rim Current periphery at the shelf off the Crimean coast. We used high resolution images of the sea surface near the Heracles Peninsula, which have become available recently. The purpose of the work is to determine the spatial-temporal characteristics of internal waves on the shelf near the Crimean coast, as well as to study the conditions for their generation based on the results of mathematical modeling and satellite observation data. 


\section{Materials and methods}

Stages of the study. The main tasks shown as stages in the scheme (Fig. 1) were accomplished. The first stage was to detect and assess the characteristics of the internal wave surface manifestations. For this purpose, we used the remote sensing data from open sources: USGS Global Visualization Viewer (GloVis), Copernicus Open Access Hub, Level-1 and Atmosphere Archive \& Distribution System Distributed Active Archive Canter (LAADS DAAC). They are based on high-resolution satellite images. The second stage was to obtain theoretical estimates of the internal waves parameters based on the development and implementation of an algorithm for solving the complete boundary value problem $[18,19]$. At the final stage, the results of theoretical and numerical studies were compared with the remote sensing data.

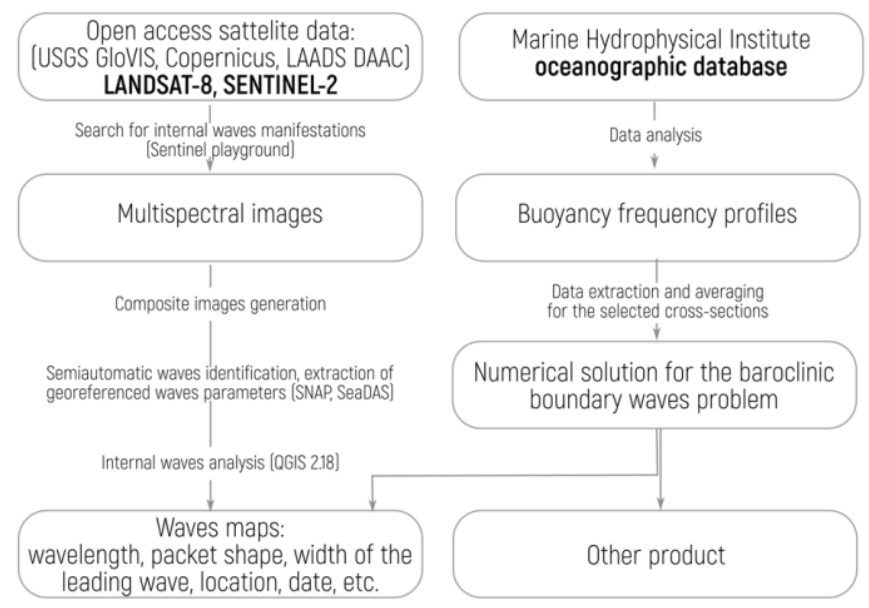

F i g. 1. Layout of the study main phases

The study area. Two vast sections of the Black Sea continental shelf near the Crimean coast are located to the southeast and north of the Heracles Peninsula. The first of them, less wide, is located between Yalta and the extreme southwestern point of the Crimean Mountains. Here, the width of the continental shelf, which has the shape of a semicircle protruding to the south, reaches about $30-40 \mathrm{~km}$. The second section (the Kalamita Bay) separated from the first one by a small narrowing of the continental shelf opposite Sevastopol extends to the northwest to Yevpatoria. Here, the deep-water areas start far to the southwest from the Crimean coast. Between these sections, the shelf is narrow and reaches $10 \mathrm{~km}$, in some areas up to $6-8 \mathrm{~km}$. Fig. 2 shows the location and serial numbers of transverse sections near the Kalamita Bay (1-10) and along the shelf between Sevastopol and Yalta (11-18).

In order to obtain new ideas about the structure of trapped waves, a series of calculations was performed on sections 1-18. The Black Sea bathymetry represented by the depth file (URL: http://www.gebco.net) was used. General Bathymetric Chart of the Oceans (GEBCO) data were obtained by combining deep bathymetric probing and satellite observations. The grid of these data is a continuous relief model of the ocean and land with a spatial resolution of $0.5^{\circ}$. 


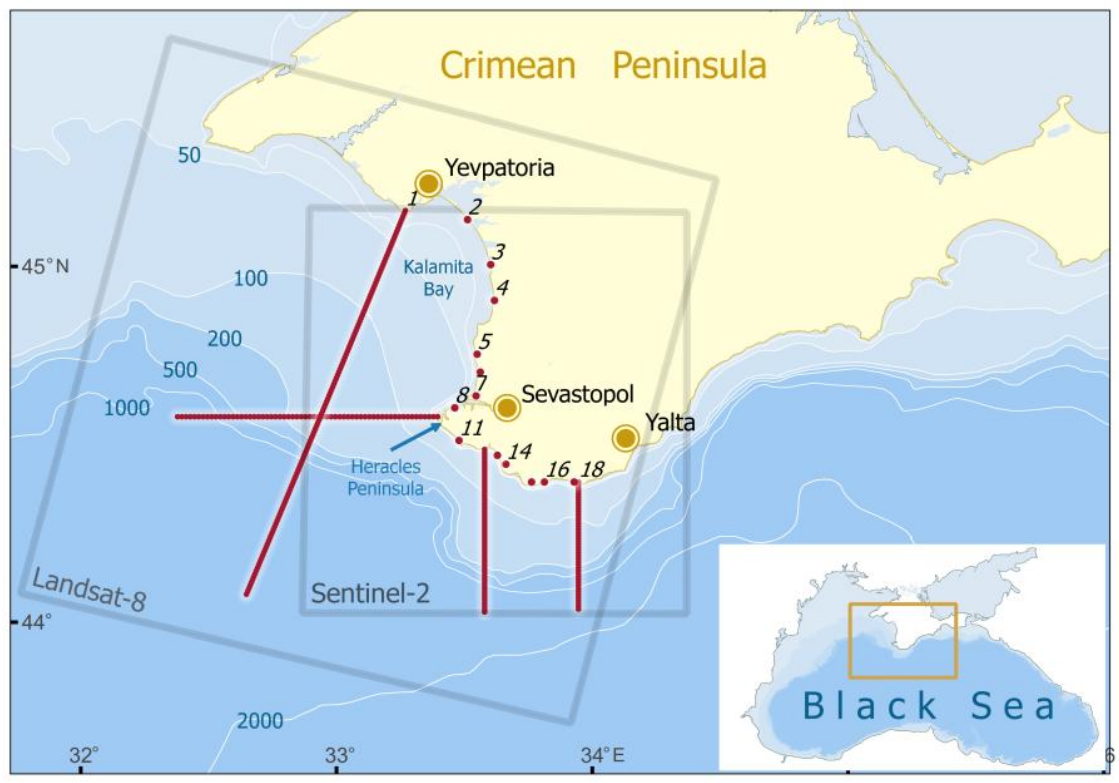

F i g. 2. Bathymetry of the Black Sea near the Crimea Peninsula. Thin white outlines denote 20-, 50-, 100-, 200-, 500-, 1000-, 2000-meter isobaths, red numbered lines - some sections considered in the numerical experiments (for the others, only the starting points are indicated), light grey rectangles the satellite data accessibility

The relief of the shelf and continental slope was approximated by two slopes shown in Fig. 3 for an idealized relief which consists of three piecewise-constant slopes: shelf, slope, and bottom of constant depth. The bottom configuration in each section is characterized by the width of the shelf $\left(L_{l}\right)$ and continental slope $\left(L_{2}\right)$, as well as the depth: near the shore $\left(h_{1}\right)$, the intermediate depth at the break point of the shelf and slope $\left(h_{2}\right)$, the depth offshore at the break point of the slope and bottom $\left(h_{3}\right)$.

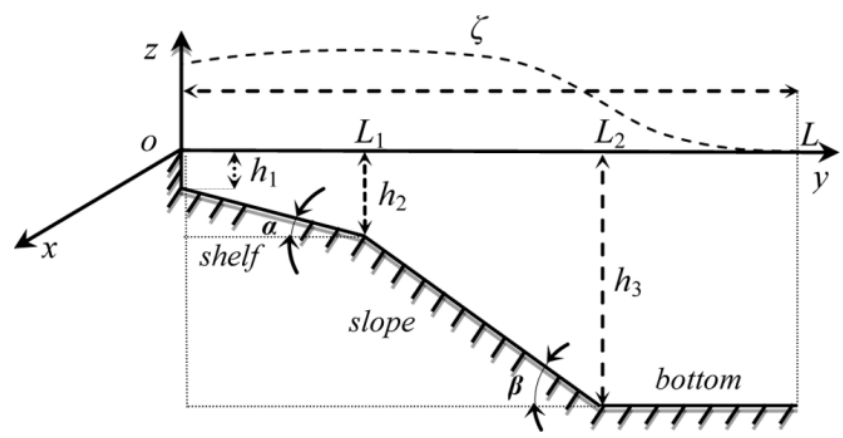

F i g. 3. Details of the idealized relief

Table 1 contains the bottom topography parameters in sections $1-18$. For each of them the values of depth $h_{1}, h_{2}, h_{3}$ and width $L_{1}, L_{2}$, as well as tilt angle for the shelf $(\alpha)$ and slope $(\beta)$ are indicated. 
Parameters of the bottom configuration on the Black Sea shelf near the Crimean coast

\begin{tabular}{c|r|c|c|c|c|c|c}
\hline \multirow{2}{*}{ Section } & \multicolumn{3}{|c|}{ Shelf } & \multicolumn{2}{c|}{ Slope } & \multicolumn{2}{c}{ Foot } \\
\cline { 2 - 8 } & $h_{1}, \mathrm{~m}$ & $L_{1}, \mathrm{~km}$ & $\alpha{ }^{\circ}$ & $h_{2}, \mathrm{~m}$ & $L_{2}, \mathrm{~km}$ & $\beta,^{\circ}$ & $h_{3}, \mathrm{~m}$ \\
\hline 1 & 2 & 75.2 & 32 & 158 & 16.0 & 45 & 1685 \\
2 & 10 & 79.0 & 30 & 145 & 15.2 & 45 & 1687 \\
3 & 6 & 75.2 & 31 & 145 & 12.0 & 45 & 1715 \\
4 & 3 & 67.3 & 33 & 160 & 13.0 & 45 & 1721 \\
5 & 7 & 48.9 & 35 & 139 & 17.8 & 45 & 1734 \\
6 & 15 & 46.7 & 35 & 129 & 21.7 & 45 & 1734 \\
7 & 9 & 50.3 & 36 & 144 & 28.9 & 44 & 1565 \\
8 & 1 & 52.8 & 38 & 202 & 31.6 & 44 & 1336 \\
9 & 1 & 52.8 & 38 & 202 & 30.3 & 44 & 1327 \\
10 & 11 & 46.2 & 38 & 189 & 27.7 & 44 & 1331 \\
11 & 1 & 17.6 & 41 & 113 & 32.5 & 45 & 1958 \\
12 & 74 & 32.4 & 34 & 150 & 18.6 & 45 & 1831 \\
13 & 65 & 24.8 & 34 & 129 & 20.8 & 45 & 1932 \\
14 & 1 & 28.2 & 40 & 161 & 15.6 & 45 & 1913 \\
15 & 1 & 28.8 & 39 & 147 & 13.8 & 45 & 1930 \\
16 & 13 & 23.3 & 40 & 149 & 16.8 & 45 & 1747 \\
17 & 14 & 23.3 & 40 & 141 & 17.7 & 45 & 1474 \\
18 & 22 & 23.2 & 38 & 119 & 16.7 & 45 & 1419 \\
\hline
\end{tabular}

The shelf near the western coast of Crimea is quite wide, $67.3-79 \mathrm{~km}$ (sections $1-4)$. At the southern coast (sections 11-18) it is on average 2.9 times narrower $\left(L_{l}=17.6-32.4 \mathrm{~km}\right)$. At sections $5-10$ its width is $46.2-52.8 \mathrm{~km}$. The slope width varies from $12.0 \mathrm{~km}$ (section 3) to $32.5 \mathrm{~km}$ (section 11), its slope is $\sim 45^{\circ}$ in all sections. From the analysis of the data in Table. 1, it follows that at the considered sections the shelf is terraced. At sections $1,3-5,7-9,11,14,15$, the edge of the shelf almost coincides with the coastline and is $1-9 \mathrm{~m}$ deepened relative to it. At sections $2,6,10,16-18$, the shelf boundary lowers to $10-22 \mathrm{~m}$. At other sections $(12,13)$, a drop in depth to $65-74 \mathrm{~m}$ is observed first, and then only one terrace.

Data sources and a method for calculating the vertical distribution of water density. The calculated fields are these of ten-day temperature and salinity at standard levels (0-1500 m layer) in the Black Sea (provided by I. G. Shokurova). In order to construct them, we used the following data from Oceanographic Data Bank of Marine Hydrophysical Institute:

-vessel measurements of temperature and salinity in 1951-2008 and temperature measurements taken by drifters since 2001;

- temperature and salinity measurements by deep-sea profiling buoys at 4-1500 m horizons (565 profiles for 2005-2008);

- monthly average nighttime satellite measurements of the sea surface temperature on a $4 \times 4 \mathrm{~km}$ grid in 1985-2007. 
The methods for constructing fields and parameters of data arrays are described in $[20,21]$. In order to calculate the vertical structure of sea water density in the sections, temperature and salinity files were selected for each of the 18 sections for 4 months, from May to August (144 files). The calculation of the of sea water density $\left(\rho, \mathrm{kg} / \mathrm{m}^{3}\right)$ was performed according to UNESCO International Equation of State [22]. The buoyancy frequency profiles $N^{2}(z)=-\frac{g}{\rho(z)} \frac{\partial \rho(z)}{\partial z}$

were calculated on the basis of the available data on the density distribution $\rho(z)$, where $z$ is the vertical coordinate, $g$ is a free fall acceleration. $\rho(z)$ and $N(z)$ profiles are tied to the grid of the indicated data.

The mathematical model. Satellite images only allow to observe and analyze the surface manifestations of internal waves. Numerical modeling can help to understand the processes occurring in the deep sea. It makes it possible to study the vertical modes of internal waves and compare the modeling results with the available satellite data. Since the purpose of this study was not to simulate all the physical processes of interaction (it is rather a demonstration of the fact that the wave features on the surface visible in satellite images reflect the manifestations of internal waves), we conducted it on the basis of solving twodimensional equations of motion. A more correct way to study intense internal waves would be to use a three-dimensional completely non-linear and nonhydrostatic system of hydrodynamic equations, which is implemented, as a rule, as a complex multi-parameter model.

The wave transformation caused by changes in the bottom topography is theoretically justified by the nonlinear shallow water equations. Internal waves can propagate along the interface between two homogeneous layers or in a continuously stratified fluid. We consider a rotating basin of variable depth filled with a stratified fluid, at $44{ }^{\circ} \mathrm{N}$. The linearized equations of motion in the Boussinesq approximation are as follows [18, 19]:

$$
\rho\left(\frac{\partial u}{\partial t}-f v\right)=-P_{x}^{\prime}, \quad \rho\left(\frac{\partial v}{\partial t}+f u\right)=-P_{y}^{\prime}, \quad \rho \frac{\partial w}{\partial t}+\rho^{\prime} g=-P_{z}^{\prime}, \quad u_{x}^{\prime}+v_{y}^{\prime}+w_{z}^{\prime}=0,
$$

where $\rho(z)$ is the sea water density; $f=1.01 \cdot 10^{-4} 1 / \mathrm{s}$ is the Coriolis parameter; $P$ is the pressure; $u, v, w$ are the components of the fluid velocity along standard orthogonal coordinates $x, y, z$, respectively. In the selected coordinate system, $x$ axis coincides with the coastline, $y$ is directed towards the open sea, $z$ is directed vertically upwards. For internal waves propagating over uneven bottom, the system of motion equations can be reduced to one equation with respect to the vertical velocity component: $w=W(z) \exp [i(k x++\omega t)]$, where $k$ is the wave number along the horizontal plane; $\omega$ is the wave frequency; $W(z)$ satisfies the equation

$$
\frac{\partial^{2} W}{\partial z^{2}}+k^{2}\left(\frac{N^{2}-f^{2}}{\omega^{2}-f^{2}}-1\right) W=0
$$

with boundary conditions

$$
W(0)=W(H)=0,
$$


where $H$ is the depth of the basin. Using the dispersion relation $\omega^{2}=C^{2} k^{2}+f^{2}$, equation (2) can be written as $\frac{\partial^{2} W}{\partial z^{2}}+\frac{N^{2}-f^{2}}{C^{2}} W=k^{2} W$. Characteristics of internal waves and vertical profiles of normal mode velocity of waves were assessed on the basis of the numerical solution of the boundary value problem [18]:

$$
\frac{\partial^{2} W}{\partial z^{2}}+\frac{N^{2}-\omega^{2}}{C_{i n}^{2}} W=0
$$

where $C_{i n}^{2}=\frac{\omega^{2}-f^{2}}{k_{n}^{2}}$, with boundary conditions (3). The approximation of derivatives in (4) by central differences and boundary conditions by one-sided differences at $n$ grid points discretized by $\Delta z$, gives the standard form of the eigenvalue problem:

$$
\mathbf{A X}=k^{2} \mathbf{X}
$$

where $\mathbf{A}$ is the tridiagonal matrix of $n \times n$ size; $\mathbf{X}$ is the column vector with elements $W(i)(i=1, \ldots, n) ; k^{2}$ is the desired set of eigenvalues. Eigenvalues in (5) were found using a program implemented in the MATLAB environment. Vertical discretization was made by splitting the $1500 \mathrm{~m}$ deep liquid column offshore and the $300 \mathrm{~m}$ at the shelf into 800 uniform intervals.

Observations of internal waves near the Crimean coast of the Black Sea. The surface manifestations of internal waves were analyzed according to satellite observations dated 2016-2017. When selecting high-resolution images from satellites Sentinel-2 and Landsat-8 from open access resources (https://scihub.copernicus.eu/dhus/\#/home, http://glovis.usgs.gov/, https://earthexplorer.usgs.g ov/), the following criteria were taken into account: the presence of the study area (in part or in whole) in the image and the sparseness of the cloud cover (since it is impermeable to optical range sensors), which makes it possible to detect and assess internal waves. The cloud cover density in the selected images varied from $0-20$ to $50-60 \%$, which was determined by the position of the clouds (above the land or the sea). The resolution of images from Sentinel-2 in the visible range (Blue, Green, Red channels, wavelengths 490$665 \mathrm{~nm}$ ) is $10 \mathrm{~m} / \mathrm{pixel}$, from Landsat-8 in the visible range (the same channels, wavelengths $480-655 \mathrm{~nm}$ ) $-30 \mathrm{~m} /$ pixel.

As a result of the search for manifestations of internal waves in the selected images, they were found only in 6 images in 2016 (out of a total of 32) and 25 images in 2017 (out of a total of 53). Thus, 37 images from Sentinel-2 and 9 from the Landsat-8 for the period from May to September 2017 were taken for analysis and comparison with modeling results.

Satellite images were read and processed using SNAP Desktop freeware. Internal wave trains were identified visually (the key signs were the presence of waves in a train, its dimensions, arched or trapezoidal train shape, brightness values of pixels): using only the optical channel at 655/665 nm wavelength (Red) or after creating an $R G B$ composite, which is an image in natural colors. If necessary, graphical contrast was applied using SNAP Desktop. 
Satellite images contain graphic and digital information with binding of each pixel to specific coordinates in latitude and longitude (WGS 84 datum). Since the SNAP Desktop software package is a geographic information system (GIS) with a minimal necessary set of tools, spatial measurements of internal wave trains were implemented. Points limiting the hexagon enclosing the wave train were determined manually with 2-4 pixels accuracy, i.e. up to 20-120 m, depending on the satellite type. The wavelength was measured as the distance between the midpoints of the contrast bands in the image corresponding to the position of the wave crests. Precision of their definition is up to 2 pixels. For each train of internal waves, the direction of its propagation, as well as 6 points contouring its shape (Fig. 4) were marked. The first point was located on the left boundary of the farthest wave in the train, the second - on the left boundary of the first wave, the third was at the center of the first wave, the fourth was at the right of the first wave, the fifth was at the right of the last wave in the train, the sixth was in the middle of the last wave. The distance between the first and second, the last and second to last waves in the train was also measured. If they coincided, then one value was put into the table, otherwise both.

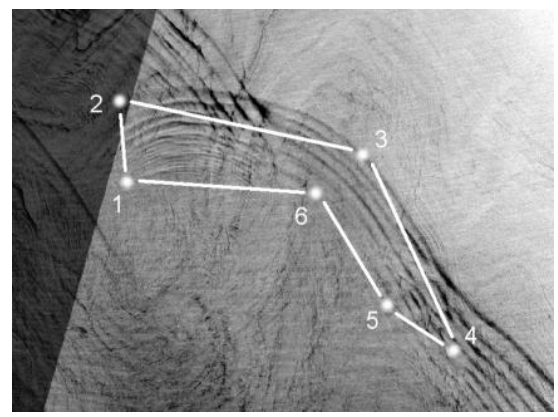

F i g. 4. Layout of the markers limiting a wave train

Each image was processed under the following conditions:

- difficulty in defining the surface manifestations of internal waves due to the phenomena that create a pronounced surface roughness (wind waves, breakings, etc.);

- weak manifestation of internal waves at the surface (they look similar to atmospheric gravitational or other surface processes);

- complicated identification of internal wave trains for which the values of the reflected component (brightness of the upward radiance) were close, i.e., the trains had an unexpressed manifestation on the surface.

In some cases, the Red channel was subtracted from the Green one, which minimized the sea surface roughness and separated the dynamic phenomena, such as eddy structures, currents, suspension transport and water fronts.

When using this method, an error in calculating spatial characteristics was determined by the following factors:

- satellite positioning accuracy - up to 6-8 m;

- satellite image resolution - 10-30 m/pixel; 
- contrast of upward radiance brightness in the image and the boundary sharpness of the studied objects (from 1 pixel at the wave front to 5-10 pixels at the lateral boundaries of the wave train, i.e., from 10-30 to 100-300 m);

- accuracy of mouse cursor positioning (500 DPI).

Summarizing, the error in measuring the boundaries of the wave train was 10-300 m.

All the obtained data were visualized using $Q G I S 2.18$ and statistically analyzed using Python programming language. Images of the obtained geo-referenced polygons were constructed to determine the areas with the most frequent manifestation of internal waves. Histograms of the occurrence frequency by month and distribution by wavelengths were performed using Matplotlib library.

\section{Analysis and discussion}

Analysis of buoyancy frequency profiles at the Black Sea shelf near the Crimean coast. In subsequent series of numerical experiments we used the profiles of buoyancy frequency averaged over 1951-2008 period. Fig. 5 shows the $N(z)$ graphs for the selected sections (Fig. 2) in the spring-summer. One can see that vertical distribution of the buoyancy frequency differs in spring (blue and green curves) and summer (red curve).

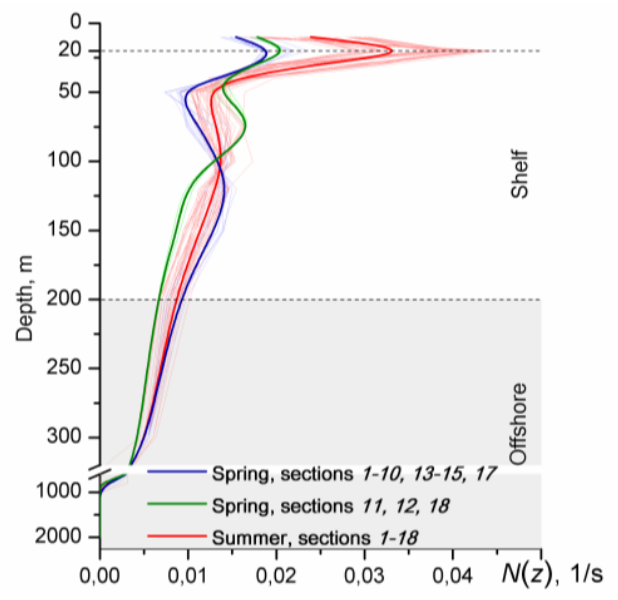

F i g. 5. Vertical profiles of buoyancy frequency $N(z)$. Thin blue lines correspond to sections $1-10$, $13-15,17$, thin green lines - to sections $11,12,18$, thin red lines - to sections 1-18; bold lines are the $N(z)$ averaged values

In spring, the maximum buoyancy frequency is observed at $20 \mathrm{~m}$ depth: from $0.0181 / \mathrm{s}$ (sections 3,4$)$ to $0.0241 / \mathrm{s}$ (section 17 ). In most $N(z)$ sections a local minimum is visible in $0.007-0.0091 / \mathrm{s}$ range at $50 \mathrm{~m}$ depth, and the second maximum lies in the range of $0.014-0.0151 / \mathrm{s}$ at $100-150 \mathrm{~m}$ depth. However, in the areas with a narrower shelf between Sevastopol and Yalta (sections 11, 18), $N(z)$ curve behaves differently: the local minimum at $50 \mathrm{~m}$ depth takes on larger values (from $0.011 \mathrm{1} / \mathrm{s}$ in section 18 to $0.0151 / \mathrm{s}$ in section 11 ), and the second maximum is shallower $(75 \mathrm{~m})$ and greater $(0.0181 / \mathrm{s})$.

In different summer months $N(z)$ graphs for the sections located normally to the coast from Yevpatoriya to Yalta look similar. Summer stratification is more 
contrasting $(N(z)$ is $0.01-0.041 / \mathrm{s})$ compared to spring $(0.01-0.021 / \mathrm{s})$. At the same time, buoyancy frequency maxima are observed at the same depth as in spring $(20 \mathrm{~m})$ and vary in June from $0.0281 / \mathrm{s}$ in section 4 to $0.0321 / \mathrm{s}$ in sections 17,18 . In the following months, the graphs shift towards the increase even more: in July the maximum is from $0.0371 / \mathrm{s}$ (sections 5,6 ) to $0.0411 / \mathrm{s}$ (sections 16, 18), in August - from $0.0401 / \mathrm{s}$ (sections 4, 5) to $0.0451 / \mathrm{s}$ (section 13). The local buoyancy frequency minimum for all sections in June and July is located at 40$50 \mathrm{~m}$ depth and amounts to $0.009-0.0131 / \mathrm{s}$. In August, it slightly falls to 50-75 m and its value rises slightly to $0.011-0.0131 / \mathrm{s}$, except for section 13 where the minimum is $0.0161 / \mathrm{s}$. The second maximum observed at $100-150 \mathrm{~m}$ depth in spring flattens in the summer. In general, water stratification was characterized by a relatively sharp interface at $50 \mathrm{~m}$ depth and less pronounced main pycnocline located at 500-1200 m depth.

Theoretical assessment of internal waves vertical velocity. In order to interpret the observations, the wave properties (Table 2) and eigenvectors for $W(z)$ vertical velocity component were calculated on the basis of equation (4). Fig. 6 shows the profiles of the internal waves vertical velocity of lower modes for 4 of 18 shelf sections according to the calculation results. The calculations were performed for buoyancy frequency profiles in different seasons (late spring and summer) (Fig. 5).

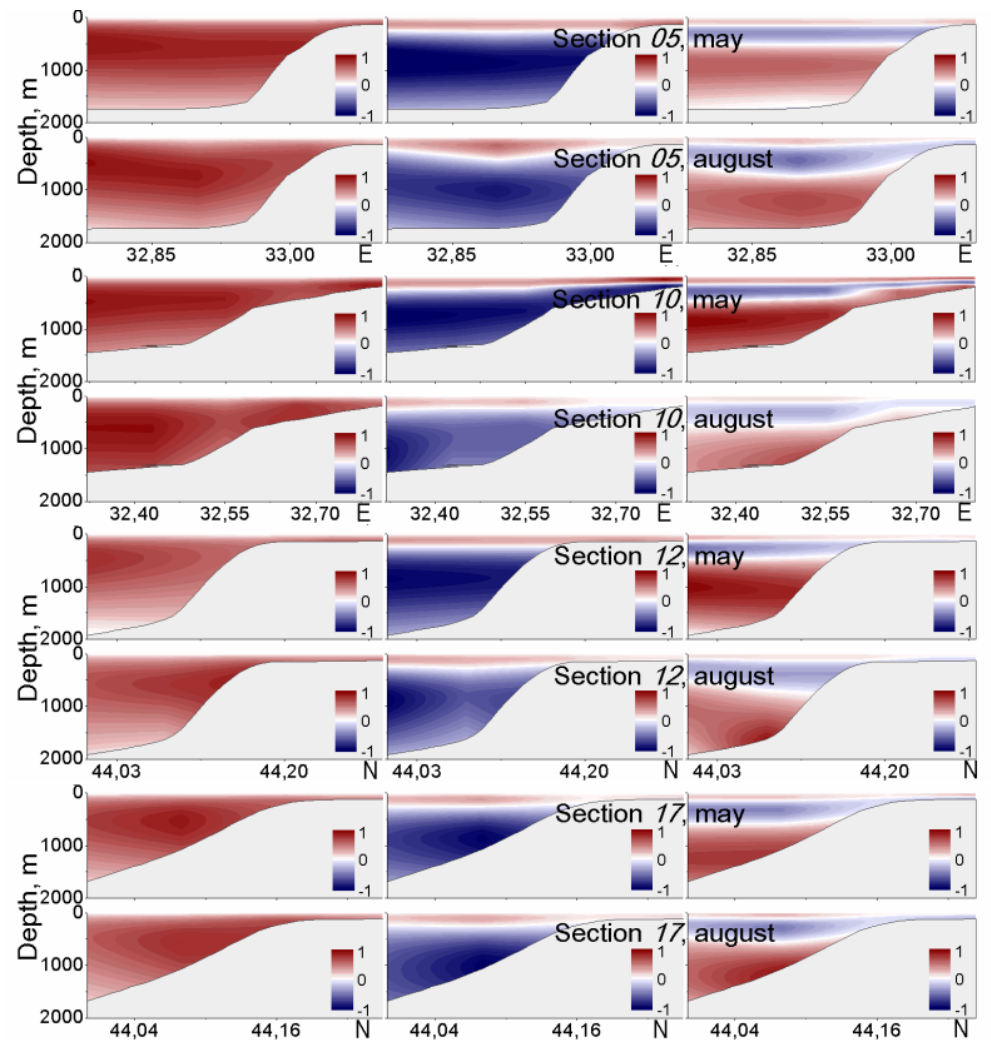

F i g. 6. Profiles of vertical velocity $W(z)$ distribution normalized from -1 to 1 along sections 5,10 , 12,17 according to the simulation results for the $N(z)$ spring and summer profiles: the first mode is on the left, the second mode - in the center, the third mode - on the right 
Spatial distribution of vertical velocity of the first mode waves was analyzed according to its profiles shown in Fig. 6 on the left. Significant vertical fluid movement (sections $10,12,17$ ) in spring is characteristic of the deep sea, and in summer of the continental slope, which is caused by more powerful flowing of the Rim Current around the shelf edge. On a shelf with a sharper slope $\left(\alpha=45^{\circ}\right)$, the maximum of vertical velocity for these seasons is located offshore. In profile 10 one can see that in summer the internal waves are generated above the shelf edge and propagate in both directions from the source of disturbances.

The highest vertical velocities of the second mode waves (Fig. 6, in the center) take place in the surface layer. The curve of zero amplitudes, passing at 150-300 m depth is placed almost horizontally in spring and bends to the bottom in summer (sections 5, 12, 17).

The profiles of vertical velocity distribution of the third mode waves (Fig. 6, on the right) confirm the effect of the bottom topography on their structure. The position of the first nodal wave line of the third mode is much closer to the sea surface (50-200 m) in comparison with the curve of zero amplitudes of the second mode waves and largely repeats its geometry. The second nodal line is located at 400-800 m depth and, as a rule, in summer it has a configuration similar to the topography of a steeply defined relief (sections $5,10,17$ ), or sharply differs from the first nodal line geometry (section 12). The highest velocity values of the third mode waves arise near the surface (100-200 m) and in deep (800-1200 m) sea. The obtained results also allow us to estimate the parameters of internal waves occurring on the Black Sea shelf near Crimea. Thus, the phase velocity of the first mode internal waves in the given sections is $2.6-5 \mathrm{~m} / \mathrm{s}$, their length is $9-180 \mathrm{~km}$ depending on the season; these features for waves of the second mode are 1.1$2.3 \mathrm{~m} / \mathrm{s}$ and $4-42 \mathrm{~km}$; for the waves of the third mode: $0.7-1.4 \mathrm{~m} / \mathrm{s}$ and $1-27 \mathrm{~km}$.

Comparison of the theoretical values of the internal waves lengths

Table 2 (the first three modes) with the data derived from the satellite images of the internal waves surface manifestations 2017

\begin{tabular}{|c|c|c|c|c|c|c|}
\hline \multirow[b]{2}{*}{ Section } & \multicolumn{2}{|c|}{ Modeling results } & \multicolumn{4}{|c|}{ Спутниковые данные } \\
\hline & Mode & $\begin{array}{c}\text { Wave } \\
\text { length, m }\end{array}$ & Date & Satellite & $\begin{array}{l}\text { Direction, } \\
\text { rhumb }\end{array}$ & $\begin{array}{c}\text { Wave } \\
\text { length, m }\end{array}$ \\
\hline \multirow{3}{*}{2} & 1 & 2416 & 25.06 .2017 & Landsat-8 & $N N W$ & 1064 \\
\hline & 2 & 950 & 30.05 .2017 & Sentinel-2 & $N E$ & 817 \\
\hline & 3 & 459 & - & - & - & - \\
\hline \multirow{3}{*}{4} & 1 & 770 & 26.06 .2017 & Sentinel-2 & $E N E$ & 707 \\
\hline & 2 & 290 & 26.06 .2017 & Sentinel-2 & $E$ & 780 \\
\hline & 3 & 210 & - & - & - & - \\
\hline \multirow{3}{*}{5} & 1 & 1197 & 28.08 .2017 & Sentinel-2 & $S S E$ & 901 \\
\hline & 2 & 596 & 11.07.2017 & Sentinel-1 & $E$ & 528 \\
\hline & 3 & 398 & - & - & - & - \\
\hline \multirow{3}{*}{10} & 1 & 996 & 28.08 .2017 & Landsat -8 & $S S E$ & 731 \\
\hline & 2 & 599 & 28.08 .2017 & Sentinel-2 & $S S E$ & 791 \\
\hline & 3 & 396 & - & - & - & - \\
\hline \multirow{3}{*}{18} & 1 & 898 & 13.09 .2017 & Landsat -8 & $E S E$ & 1142 \\
\hline & 2 & 498 & 26.06.2017 & Sentinel-2 & $N E$ & 391 \\
\hline & 3 & 396 & - & - & - & - \\
\hline
\end{tabular}


Comparison of model calculations and observations using satellites. 129 cases of internal wave propagation were defined from May to September 2017 (Fig. 7). The distribution by months is uneven: the largest number of waves (50) was observed in June, while in May and September only 12 and 6, respectively. From July to August, the number of waves decreases from 42 to 19. Qualitative analysis shows that the regions of their occurrence are located northwards from the Heracles Peninsula (where the quasistationary Sevastopol anticyclone forms) and to the north-west of it, in the shallow Kalamita Bay. Over the wider shelf, the waves propagate mainly towards the coast, over the narrower shelf - along it. The waves propagated mainly in NNE, NE and ENE directions (62 cases out of 129).

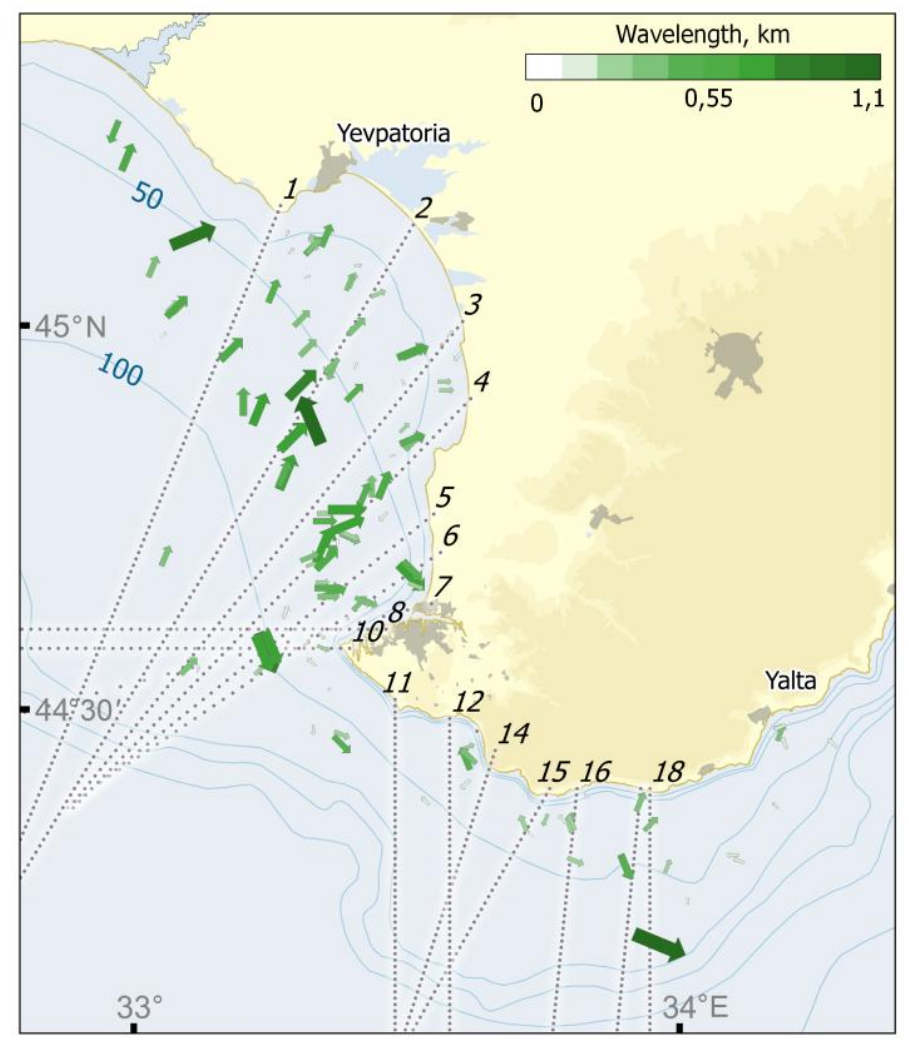

F i g. 7. Diagram of the internal waves manifestations constructed using the satellite data. Numbered lines are the sections considered in numerical experiments

The wavelengths varied within $0.05-1.14 \mathrm{~km}$ with an average of $0.4 \mathrm{~km}$ and a median $0.375 \mathrm{~km}$, which is very close to the average. Moreover, the most pronounced waves were $0.15-0.6 \mathrm{~km}$ long. The longest waves, about $1.1 \mathrm{~km}$, were observed northward from Sevastopol to Yevpatoriya along the 50-meter isobath (Fig. 7). In some cases (99 out of 129), the dispersion of the waves was observed in the images, i.e. a decrease in the wavelength within one train by $0.1-0.3 \mathrm{~km}$. Most of the trains had a trapezoidal shape expanding in the direction of its propagation. 
The average front width is $9.6 \mathrm{~km}$ with a median of $7.6 \mathrm{~km}$ and a maximum value of $40 \mathrm{~km}$.

Analysis of satellite observations is indicative of the two-dimensional spatial structure and frequency of internal waves manifestations. It was revealed that they propagate in different directions relative to the coastline and shelf edge (Fig. 8).

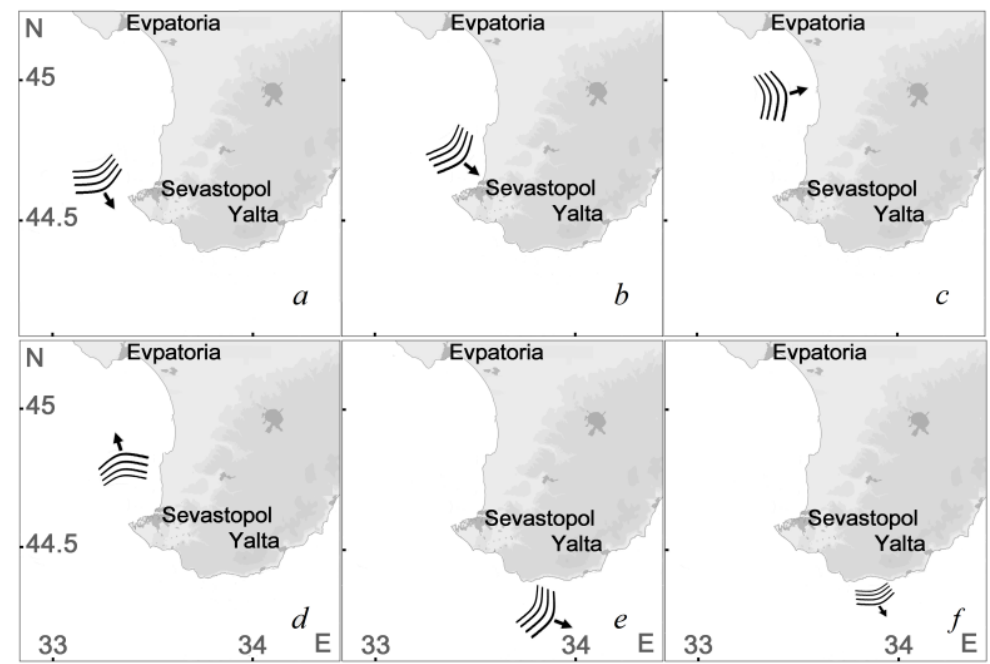

F i g. 8. Sketch maps showing direction of the internal waves propagation relative to the coastline or the shelf edge: almost parallel to the coastline $(a, d, e)$; towards the coastline $(b, c)$; from the coastline $(f)$

In the given sketch maps we marked internal waves propagating in the following directions: parallel to the coastline and the shelf edge (Fig. 8, $a, d, e$ ); towards the coastline near Sevastopol (Fig. 8, b) and Saki (Fig. 8, c); from the coastline (Fig. 8, f). The types of wave directions shown in Fig. 8, $b, c$ prevailed in the analyzed period.

Internal waves are gravitational waves that propagate along the interface of water layers with different densities. Density stratification boundaries of pycnocline are the primary condition for internal waves, but it does not determine their parameters in all cases. This is due to the fact that any hydrostatically stable density stratification is sufficient to maintain internal waves [23]. In addition to the main mechanism for the formation of intense internal waves at the Black Sea shelf, there are other well-known ones:

- generation by intrusion of desalinated water;

- generation by internal inertial waves and local fronts of surge origin coming to the coastal zone;

- generation during the passage of a compact submesoscale eddy along the shelf;

- generation when internal tidal bores come to the coastal zone;

- generation by atmospheric fronts.

In order to separate the internal waves caused by the mentioned mechanisms from the waves caused by the main generation mechanism, we compared 
the values of the internal wave parameters obtained from the model and satellite data.

For interpreting the data, compare the calculated wave properties of $W(z)$ vertical velocity component described by equation (4). The results of modeling performed using the calculated $N(z)$ values for the selected sections are compared with the results obtained by processing the satellite information about the surface manifestations of internal waves (Table 2). These parameters were compared according to the modeling data obtained on sections near the determined trains of internal waves (Fig. 7). Two values correspond to the lengths of the first and last waves in the train. The wavelengths near section 2 can correspond to the theoretical values of the second mode of internal waves, near section 4 - to the values of the first mode, near section 5 - to these of the first or second mode, near section $18-$ to the values of the third mode (Table 2). The results of internal waves manifestations in section 10 do not correspond to the lower modes of internal waves, which suggests other mechanisms for their formation.

In 98 out of 129 observed cases of internal waves manifestation, the wavelength increased when approaching the coast. This indirectly indicates the two-layer stratification of the sea and the possibility of applying the dispersion relation from [24] to our case, when the wavelength (hundreds of meters) is large only in comparison with the upper layer (tens of meters), but comparable with the lower layer $(100-150 \mathrm{~m}): c_{\mathrm{IW}}=\sqrt{\frac{g^{\prime} h_{1}}{1+k h_{1} c t h\left(k h_{2}\right)}}$, where $h_{1}$ is the upper layer thickness, $h_{2}$ is the lower layer thickness; $g^{\prime}=g \Delta \rho / \rho$. This result will allow us to obtain the phase velocity of the waves from subsequent satellite images and to calculate the depth of the maximum - Brunt-Väisälä frequency if the wave mode structure and the typical density difference in the selected region are known.

\section{Conclusions}

Based on satellite sensing data and the results of analytical calculations, the main spatial-temporal characteristics of internal waves in the Black Sea shelf zone near the Crimean coast were determined. The assumption about the reason for the generation of intense internal waves caused by the Rim Current jet interaction with the shelf edge was confirmed by the results of numerical calculations of the vertical distribution of wave velocity of the first three modes. The performed mathematical modeling provided the theoretical estimates of internal waves parameters depending on the season and the coastal relief.

Comparing the lengths of the observed and calculated waves we can conclude that in 2017 the waves of the second and third modes in the study area were observed from the satellites most often. They propagated down to $1200 \mathrm{~m}$ depth and usually manifested themselves most intensely $20-30 \mathrm{~km}$ from the coast, depending on the shelf width and the water density vertical profile. The longest waves, about $1.1 \mathrm{~km}$, were observed northward from Sevastopol to Yevpatoriya along the 50-meter isobath. 


\section{REFERENCES}

1. Serebryany, A.N. and Ivanov, V.A., 2013. Study of Internal Waves in the Black Sea from Oceanography Platform of Marine Hydrophysical Institute. Fundamental'naya $i$ Prikladnaya Gidrofizika, 6(3), pp. 34-45 (in Russian).

2. Goncharov, V.V., Ivanov, V.N., Kochetov, O.Yu., Kuryanov, B.F. and Serebryanyi, A.N., 2012. Acoustic Tomography at Shelf of the Black Sea. Acoustical Physics, [e-journal] 58(5), pp. 562-570. doi:10.1134/S1063771012030050

3. Zatsepin, A.G., Ostrovskii, A.G., Kremenetskiy, V.V., Nizov, S.S., Piotukh, V.B., Soloviev, V.A., Shvoev, D.A., Tsibul'sky, A.L. and Kuklev, S.B. [et al.], 2014. Subsatellite Polygon for Studying Hydrophysical Processes in the Black Sea Shelf-Slope Zone. Izvestiya, Atmospheric and Oceanic Physics, [e-journal] 50(1), pp 13-25. doi:10.1134/S0001433813060157

4. Ivanov, V.A. and Serebryanyy, A.N., 1985. [Short-Period Internal Waves in Coastal Waters of Non-Tidal Sea]. Izvestiya AN SSSR. Fizika Atmosfery i Okeana, 21(6), pp. 648-656 (in Russian).

5. Vlasenko, V.I., Ivanov, V.A., Krasin, I.G. and Lisichenok, A.D., 1998. The Generation of Intensive Short-Period Internal Waves in the Frontal Zone of a Coastal Upwelling. Physical Oceanography, [e-journal] 9(3), pp. 155-168. https://doi.org/10.1007/BF02523226

6. Kao, T.W., Pao, H.-P. and Park, C., 1978. Surface Intrusions, Fronts, and Internal Waves: A Numerical Study. Journal of Geophysical Researches, [e-journal] 83(C9), pp. 4641-4650. doi:10.1029/JC083iC09p04641

7. Bedritskii, A.I., Asmus, V.V., Krovotyntsev, V.A., Lavrova, O.Yu. and Ostrovskii, A.G., 2009. Space Monitoring of Pollution of the Russian Sector of the Azov-Black Sea Basin in 2008. Russian Meteorology and Hydrology, [e-journal] 34(3), pp. 137-147. doi:10.3103/S1068373909030017

8. Bondur, V.G., Troitskaya, Yu.I, Ezhova, E.V., Kazakov, V.I., Kandaurov, A.A., Sergeev, D.A. and Soustova, I.A., 2018. Surface Manifestations of Internal Waves Induced by a Subsurface Buoyant Jet (Experiment and Theory). In: M. Velarde, R. Tarakanov, A. Marchenko, eds, 2018. The Ocean in Motion. Cham: Springer, pp. 67-85. doi:10.1007/9783-319-71934-4_8

9. Bulatov, V.V. and Vladimirov, Y.V., 2018. Internal Gravity Waves in Horizontally Inhomogeneous Ocean. In: M. Velarde, R. Tarakanov, A. Marchenko, eds, 2018. The Ocean in Motion. Cham: Springer, pp. 109-126. doi:10.1007/978-3-319-71934-4_10

10. Lavrova, O.Yu., Mityagina, M.I., Sabinin, K.D. and Serebryany, A.N., 2015. Study of hydrodynamic Processes in the Shelf Zone Based on Satellite Data and Subsatellite Measurements. Sovremennye Problemy Distantsionnogo Zondirovaniya Zemli iz Kosmosa, 12(5), pp. 98-129 (in Russian).

11. Lavrova, O.Yu. and Mityagina, M.I., 2017. Satellite Survey of Internal Waves in the Black and Caspian Seas. Remote Sensing, 9(9), pp. 892-918. doi:10.3390/rs9090892

12. Dulov, B.A., Yurovskaya, M.V. and Kozlov, I.E., 2015. Coastal Zone of Sevastopol on High Resolution Satellite Images. Physical Oceanography, [e-journal] (6), pp. 39-54. doi:10.22449/1573-160X-2015-6-39-54

13. Serebryany, A.N., 2012. Slick- and Suloy Generating Processes in the Sea. Internal Waves. Sovremennye Problemy Distantsionnogo Zondirovaniya Zemli iz Kosmosa, 9(2), pp. 275-286 (in Russian).

14. Fedorov, K.N. and Ginsburg, A.I., 1986. Phenomena on the Ocean Surface According to Visual Observations. Okeanologiya, 26(1), pp. 5-14 (in Russian).

15. Lavrova, O.Yu., Mityagina, M.I., Sabinin, K.D. and Serebryany, A.N., 2011. Satellite Observations of Surface Manifestations of Internal Waves in the Caspian Sea. Izvestiya, Atmospheric and Oceanic Physics, [e-journal] 47(9), pp. 1119-1126. doi:10.1134/S000143381109009X 
16. Mityagina, M.I., Lavrova, O.Y. and Karimova, S.S., 2010. Multi-Sensor Survey of Seasonal Variability in Coastal Eddy and Internal Wave Signatures in the North-Eastern Black Sea. International Journal of Remote Sensing, [e-journal] 31(17-18), pp. 4779-4790. doi:10.1080/01431161.2010.485151

17. Lavrova, O.Yu., Mityagina, M.I. and Sabinin, K.D., 2011. Study of Internal Wave Generation and Propagation Features in Non-Tidal Seas Based on Satellite Synthetic Aperture Radar Data. Doklady Earth Sciences, [e-journal] 436(1), pp. 165-169. doi:10.1134/S1028334X11010272

18. Yankovsky, A.E. and Zhang, T., 2017. Scattering of a Semidiurnal Barotropic Kelvin Wave into Internal Waves over Wide Continental Shelves. Journal of Physical Oceanography, [ejournal] 47(10), pp. 2545-2562. doi:10.1175/JPO-D-16-0284.1

19. Mysak, L.A., 1980. Recent Advances in Shelf Wave Dynamics. Reviews of Geophysics, [ejournal] 18(1), pp. 211-241. doi:10.1029/RG018i001p00211

20. Belokopytov, V.N. and Shokurova, I.G., 2005. Estimates of temperature and salinity interdecadal variability in the Black Sea during 1951-1995. In: MHI, 2005. Ekologicheskaya Bezopasnost' Pribrezhnoy i Shel'fovoy Zon i Kompleksnoe Ispol'zovanie Resursov Shel'fa. Sevastopol: MHI. Iss. 12, pp. 12-21 (in Russian).

21. Zhuk, E.V., Khaliulin, A.Kh., Ingerov, A.V., Godin, E.A., Plastun, T.V. and Isaeva, E.A., 2016. Information Resources of FSBSI MHI Oceanographic Data Bank for Supporting Environmental Research of the Black Sea Coastal Area. In: G. G. Matishov, ed., 2016. [Ecology. Economy. Informatics]. Rostov-on-Don: YuNTs RAN. Vol. 2(1), pp. 81-92 (in Russian).

22. Fofonoff, N.P. and Millard Jr., R.C., 1983. Algorithms for Computation of Fundamental Properties of Seawater. UNESCO technical papers in marine science 44, p. 53. Available at: http://unesdoc.unesco.org/images/0005/000598/059832eb.pdf [Accessed: 15.09.2018].

23. Garrett, C. and Munk, W., 1979. Internal Waves in the Ocean. Annual Review of Fluid Mechanics, (11), pp. 339-369. doi:10.1146/annurev.fl.11.010179.002011

24. Konyaev, K.V. and Sabinin, K.D., 1992. [Waves Inside the Ocean]. Saint-Petersburg: Gidrometeoizdat, 272 p. (in Russian).

About the authors:

Vitaliy A. Ivanov - the Head of Coastal Research Scientific Direction, Marine Hydrophysical Institute of RAS (2 Kapitanskaya Str., Sevastopol, 299011, Russian Federation), Academician of RAS, Dr.Sci. (Phys.-Math.), Professor, ResearcherID: I-7436-2013, vaivanov@mhi-ras.ru

Tatiana Ya. Shul'ga - Senior Research Associate, Marine Hydrophysical Institute of RAS (2 Kapitanskaya Str., Sevastopol, 299011, Russian Federation), Ph.D. (Phys.-Math.), ORCID ID: 0000-0002-7873-6697, ResearcherID: P-9894-2015, SPIN-code: 2423-6440, shulgaty@ mail.ru

Andrei V. Bagaev - Senior Research Associate, Marine Hydrophysical Institute of RAS (2 Kapitanskaya Str., Sevastopol, 299011, Russian Federation), Ph.D. (Phys.-Math.), ORCID ID: 0000-0003-4018-7642, ResearcherID: K-5373-2016, SPIN-code: 5426-7176, a.bagaev1984@gmail.com

Alesia V. Medvedeva - Junior Research Associate, Marine Hydrophysical Institute of RAS (2 Kapitanskaya Str., Sevastopol, 299011, Russian Federation), ORCID ID: 0000-0001-7856-623X, shift@mail.ua

Tat'yana V. Plastun - Junior Research Associate, Marine Hydrophysical Institute of RAS (2 Kapitanskaya Str., Sevastopol, 299011, Russian Federation), SPIN-code: 7165-6187, ptv63@inbox.ru

Liudmila V. Verzhevskaia - Leading Specialist, Marine Hydrophysical Institute of RAS (2 Kapitanskaya Str., Sevastopol, 299011, Russian Federation), ORCID ID: 0000-0002-1547-7966, ResearcherID: R-4253-2018, SPIN-code: 7309-7879, ludmyla.ver@mhi-ras.ru 
Irina A. Svishcheva - Junior Research Associate, Marine Hydrophysical Institute of RAS (2 Kapitanskaya Str., Sevastopol, 299011, Russian Federation), ORCID ID: 0000-0003-1501-3720, ResearcherID: M-4451-2018, svishcheva.iryna@gmail.com

Contribution of the co-authors:

Vitaliy A. Ivanov - general scientific management of research, development and scientific justification of the research concept, statement of the problem, formulation of conclusions, editing and supplementing the text of the paper

Tatiana Ya. Shul'ga - analysis of materials in Russian and foreign sources on research methods, studying and developing the concept, statement of the research problem, development of methods and experimental studies, qualitative and quantitative analysis of the results of the study and preparation of initial conclusions, preparation of the text of the paper

Andrei V. Bagaev - statement of the problem of searching for manifestations of internal waves, analysis of satellite image processing results, preparing and analyzing image information using QGIS, preparation of the text of the article and figures

Alesia V. Medvedeva - search and retrieval of remote sensing data, selection of satellite images with the studied objects, processing satellite images in GIS

Tat'yana V. Plastun - collection of available materials on the topic of research, development and debugging of a computer program for data processing, formalized data analysis, construction of graphs, figures, editing and supplementing the text of an article

Liudmila V. Verzhevskaia - construction of graphs, drawings, finalization of the text of the article

Irina A. Svishcheva - formalized data analysis, processing data using a computer program, visualization of data in the text, construction of graphs, figures

All the authors have read and approved the final manuscript.

The authors declare that they have no conflict of interest. 